\title{
Anthropometric Database of the Preschool Children from 2 to 6 Years in Taiwan
}

\author{
I-Fang Cheng ${ }^{1} \cdot \mathrm{Li}_{-C h i e h} \mathrm{Kuo}^{2} \cdot$ Chien-Ju Lin ${ }^{3} \cdot$ Hsiao-Feng Chieh ${ }^{4} \cdot$ Fong-Chin Su ${ }^{1,3}$
}

Received: 10 December 2017 / Accepted: 26 June 2018 / Published online: 9 July 2018

(c) The Author(s) 2018

\begin{abstract}
Anthropometry is important in product or environment designs based on humanfactors. Specific anthropometric databases should be established for certain ofpopulations, especially for different genders, ages and races. In this study, 5772preschool children (from two to six years old) were recruited. An electromagneticmotion analysis system, measuring tape, an electronic scale and electronic caliperswere used to measure the basic data, structural and postural dimensions. Differencesin stature and weights were found in preliminary comparisons with children of the sameage in Japan and the United States. It is supposed that ethnic diversity leads to variedbody dimensions in children. This study established a large-scale and reliableanthropometric database of preschoolers which provides a practical reference fordesigns aimed at Taiwanese children. Accordingly, it is anticipated that the safety andsuitability of products and environments made for Taiwanese children can advancewith regard to ergonomics.
\end{abstract}

Keywords Anthropometry $\cdot$ Children $\cdot$ Preschool $\cdot$ Product design $\cdot$ Environment design

\section{Introduction}

Anthropometry plays a very important role in fields such as clothing design, industrial design, and architecture. It also can be regarded as the basis of ergonomics, which has become increasingly important because of its ability to prevent injuries and increase comfort. Previous studies have found evidence for an association between pain or discomfort at work and an ergonomically deficient workplace or poorly structured job [1]. It has been indicated that neck

Electronic supplementary material The online version of this article (https://doi.org/10.1007/s40846-018-0436-4) contains supplementary material, which is available to authorized users.

Fong-Chin Su

fcsu@mail.ncku.edu.tw

1 Department of Biomedical Engineering, National Cheng Kung University, 1 University Road, Tainan 701, Taiwan

2 Department of Occupational Therapy, National Cheng Kung University, Tainan, Taiwan

3 Medical Device Innovation Center, National Cheng Kung University, Tainan, Taiwan

4 Musculoskeletal Research Center, National Cheng Kung University, Tainan, Taiwan and shoulder pain in computer workers might result from poor posture [2]. Not only adults but also children have been studied in this regard and it was found that ergonomic mismatches between the physical dimensions and classroom furniture might be associated with musculoskeletal discomforts [3-9], while improper backpack carrying has been shown to lead to chronic musculoskeletal pain to schoolchildren [10]. It was also indicated that the design of school furniture would influence schoolchildren's learning behavior and health $[6,11]$. Moreover, there is less muscle activity in the latissimus dorsi when children sit at an ergonomics workstation than that at a traditional one [12].

Designs based on inaccurate physical dimensions are an important factor in the development of musculoskeletal disorders, as they encourage poor posture over a long period of time. Improper product design and environmental planning are also associated with a greater incidence of injuries even may result in a fatal hazard. For example, in New Zealand four children under 5 years old die each year from injuries related to infant furniture [13]. In addition, it is suggested that all playground equipment should be designed specifically for the physical dimensions of preschool children [14]. Therefore, it is reasonable to suggest that anthropometry should be taken into account when designing products, such as hand tools or furniture. In particular for children, whose 
bodies are growing and changing rapidly, appropriate applications of anthropometric data in product design should be undertaken to decrease the occurrence of musculoskeletal problems, such as back pain and scoliosis, due to long periods using unsuitable desks and chairs.

Since the 1940s, several developed countries have been working on the establishment of anthropometric databases of their military, workforce or citizens in general. Worldwide, there are at present more than 90 large scaled anthropometric databases, and most of them focus on Western populations. However, there are less than 10 in Asia, of which more than half are in Japan (IOSH, 1997). Asian countries account for more than $60 \%$ of the world population, but have relatively fewer anthropometric databases. Besids, differences in nutrition and life style, as well as hereditary and ethnic factors, lead to difference in body sizes and dimensions [15-18]. In Asia, even among ethnic groups which are historically closely associated, such as the Taiwanese, Japanese, Koreans and mainland Chinese, differences in body shape and bodily proportions have been found [19]. In additions, not only different ethnicity, but also nutrition, living style and environment are very likely to contribute to differences in body size and dimensions [20]. Local anthropometry database should be established as reference and basis for safe environmental, industrial designs or related research for different ethnic groups.

However, most of these databases were built only for adults with the aim of increasing industrial safety, and much less attention has been paid to adolescents and children. It is likewise in Taiwan, several anthropometric databases of adults have been established with the support of the Institute of Occupational Safety and Health and Nation Science Council, but there is no anthropometric database for young children. This may be due to the difficulties of assessing those miscellaneous anthropometric data from the younger children, there are few studies published on anthropometrics and ergonomics issues of the children aged from two to six. Although most of the research conducted was ergonomically designed furniture for adults, the appropriateness and safety of the products and environments for children have gained more and more attention in recent years. According to the report of Child Growth Standards and Growth Reference 5-19 Years from the website of World Health Organization, it shows a period of rapid growth and development from birth, and growth rate slows down until adolescence, indicating that the body dimensions vary significantly from birth to adolescence. However, most of the anthropometric studies were conducted on the children older than 6 years except preschool-aged ones. As to the population under 18, there are few reliable and official anthropometric databases of adolescents [21], and no anthropometric data for preschool children. Safety and suitability are the main concerns for products and environment designs for children, such designs depend on the accurate measurements of physical dimensions, highlighting the importance of quality anthropometric data [14]. In Taiwan, product designs are generally based on anthropometric data obtained from Western children, but previous studies have found that ethnicity plays an important role in body size [15-18]. Even in the neighboring regions, such as Taiwan and Japan, significant differences in human anthropometry still exist [19].

For these reasons, the main aim of this study is to establish a local anthropometric database of 2 to 6-year-old children residing in Taiwan, so as to provide an anthropometric reference for Taiwanese children's body size and dimensions that can then be used in the designs of clothing, industrial products, toys, and the planning of the environment for the children in Taiwan. In additions, ethnical difference was investigated by comparing the basic anthropometric data of Taiwanese preschool children to that obtained in other countries.

\section{Methods}

\subsection{Participants}

In order to reduce the effects arising from differences between the city and country, the participants were recruited from kindergartens in southern, central and northern Taiwan, in a ratio based on the population distribution (northern: $45 \%$, central: $26 \%$, and southern: $26 \%$ ). With the permission of their parents or guardians, 5772 children (3041 boys and 2731 girls), aged from two to six $^{1}$, participated in the study. Children were excluded if they had significant physical deficiencies or diagnoses of neuromuscular disease, such as cerebral palsy and Down syndrome. The present study was approved by the Institutional Review Board of National Cheng Kung University Hospital (Tainan, Taiwan). Furthermore, the recruitment of these subjects was carried out with the support and assistance of Ministry of Education in Taiwan.

\subsection{Apparatus}

In order to ensure the unity of testing postures among children, an adjustable frame (Fig. 1) was manufactured. The stature of each participant was measured with a measuring tape fixed to the back board, while their weight was measured with an electronic scale. A flexible measuring tape was used to measure the circumferences, such as those of the head, thigh and calf. An electronic caliper was used to

\footnotetext{
${ }^{1}$ Definition of age: age 2 means 2 year 0 month to 2 year 11 month, age 3 means 3 year 0 month to 3 year 11 month, and so on.
} 


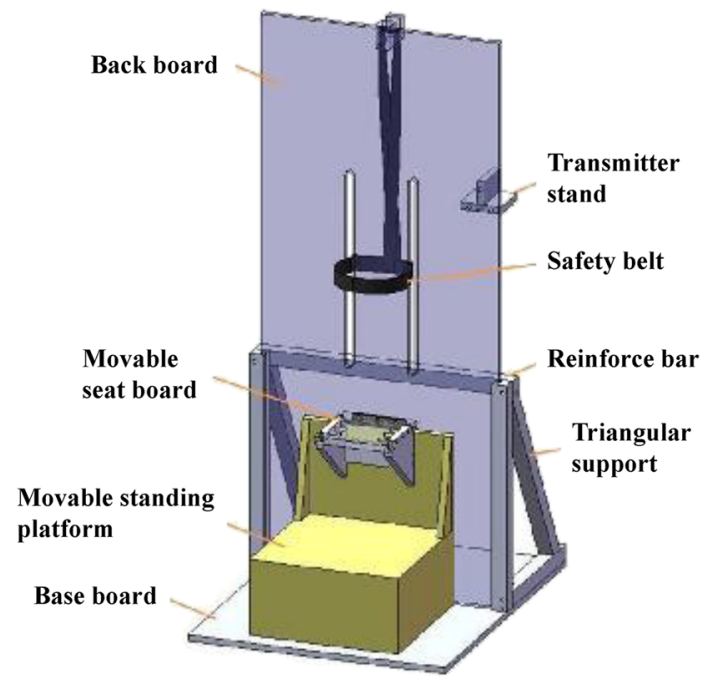

(a) Adjustable frame

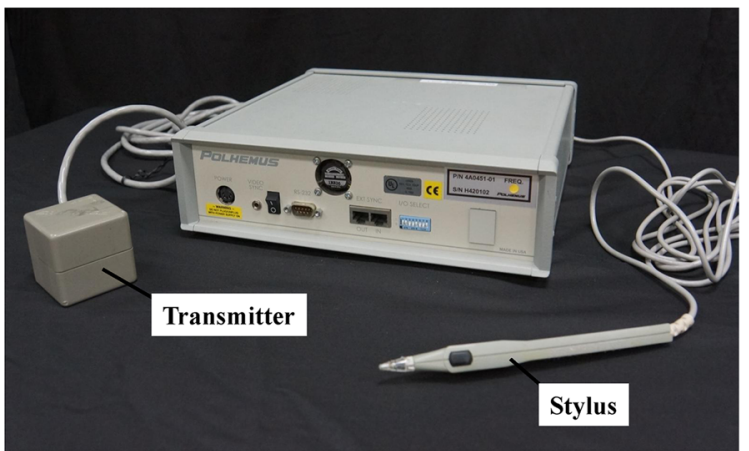

(b) 3SPACE FASTRAK

Fig. 1 Apparatus in the study

measure the widths, such as hip width. In addition, an electromagnetic motion analysis system (3SPACE FASTRAK, Fig. 1) was used to locate the physical landmarks in three different positions (standing, sitting and squatting) on the standing board to account for body structure dimensions as well as postural dimensions. To ensure safety and stability throughout the measurement process, a mounted and adjustable frame with a safety belt (Fig. 1) was designed and used to stabilize the participants in different postures.

\subsection{Experimental Process}

Firstly, the personal details of each participant, such as the birth date, were given by the parents or kindergarten teachers. Dominant hands were determined according to their hand preferences in writing, drawing, throwing ball, using spoon or scissors depending on their ages. Dominant legs were determined according to their leg preferences in kicking balls or jumping on one leg. After the measurement of stature and weight, the participant was instructed to stand erectly on the adjustable frame with appropriate stability. The participant was asked to lean his/her rear head, back, buttock, arms and heels on the back board and to remain still in anatomy position. The stylus of the electromagnetic motion analysis system was used to locate the landmarks on the surface of the skin referring to modified Helen Hayes marker set reference and definitions of anthropometric measurements [22]. In addition, the positions of the ground, the seat surface and the back board were recorded as the reference points for calculation of postural dimensions.

In the measurements of this study, anthropometric values of dominant segments were measured on the supposition of bilateral symmetry. First, when participants were standing in the anatomical position, the landmarks recorded were the forehead, rear head, lobule, bilateral acromions, bilateral axillae, xiphoid process, lateral epicondyle of humerus, styloid process of radius, tip of middle finger, superior border of patella, and lateral malleolus dominant sides. Subsequently, the participant was asked to extend one of his/ her wrist of dominant hand until palm was parallel to the ground. In which hand position, the palm center was located to measure the height of the palm center from the ground. Additionally, with the hand fisted, the participant was asked to raise one of his/her arms with extended elbow as high as possible, besides, to flex both elbows to $90^{\circ}$ with upper arms at the side of the trunk. In these two positions, the center of the fist and bilateral olecranon processes were located. All the required positions and available dimensions in standing were illustrated in Fig. 2.

Following the standing position, the participant was instructed to sit erectly on the seat board with the hip and knee flexed at $90^{\circ}$ and to lean his/her back on the back board. The positions of acromion, olecranon process with flexed elbow at $90^{\circ}$, buttock, superior border of patella, anterior tip of knee, popliteal fossa were recorded. Moreover, the center of the fist was also located when the participant raised his/ her arm with extended elbow. The required positions and available dimensions in sitting were illustrated in Fig. 3 .

Several physical dimensions of the hand were measured with the hand being well supported in sitting position. Firstly, the participant's hand was kept in neutral position with adducted fingers, in which pose heads of the 1st, the 2nd, and the 5th metacarpals were located. On the volar side, tip and base of middle finger, as well as midpoint of rascette 
Fig. 2 Positions and available dimensions in standing

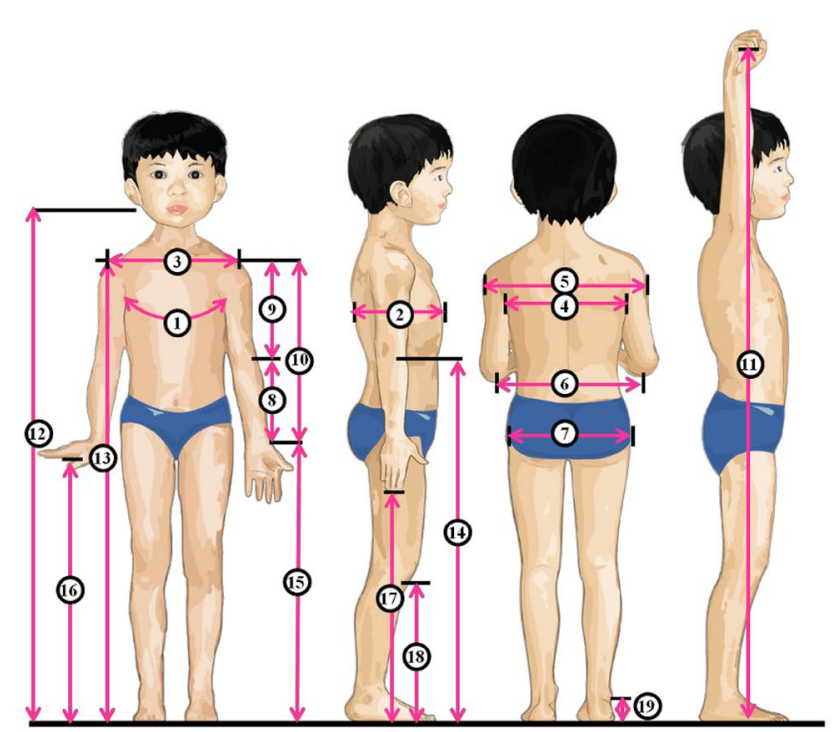

1. Chest circumference

2. Bust depth

3. Biacromial breadth

4. Interscye

5. Bideltoid breadth

6. Elbow-elbow breadth

7. Hip breadth

8. Forearm length

9. Upper arm length

10.Arm length

11. Vertical grip reach

12.Lobule height

13. Shoulder height

14.Elbow height

15. Wrist height

16.Palm center height

17.Middle finger tip height

18. Knee height

19.Ankle height
Fig. 3 Positions and available dimensions in sitting

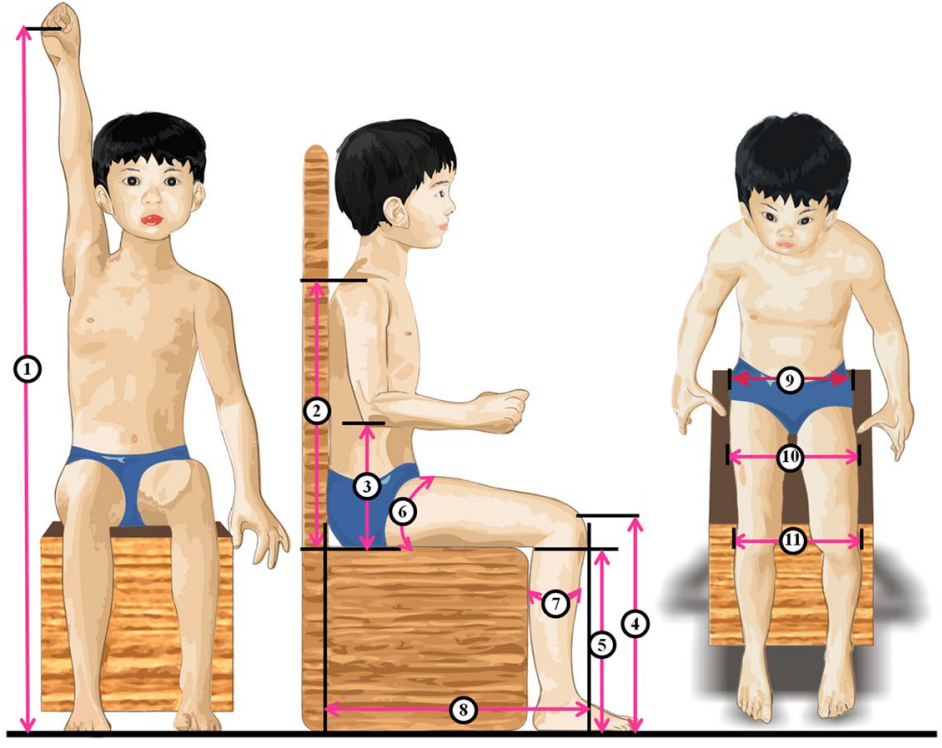

1. Vertical grip reach

2. Shoulder height

3. Elbow height

4. Knee height

5. Popliteal height

6. Thigh circumference

7. Calf circumference

8. Buttock-knee length

9. Hip breadth

10. Thigh-thigh breadth

11.Knee-knee breadth (wrist wrinkle) were located. In fisting pose, base and head of the 3rd proximal phalanx were located. Additionally, the participant was asked to make a circle-shape by opposing thumb tip to index tip and middle finger tip respectively, in which two poses contact points and metacarpal-phalangeal joints of index and middle finger were located to calculate the diameter of the circle. The illustrations of measuring dimensions were shown in Fig. 4.

The participant was then asked to change his/her posture to squatting positions, in which feet placements and squatting patterns could be self-selective for appropriate stability because immature squatting balance control is common in young children. In squatting position, the top of head, the most anterior, posterior and bilateral points of body were located, so that three postural dimensions could be measured as the Fig. 5 shows.

Following the location of physical landmarks with the electromagnetic motion analysis system, the breadths and circumferences of the body segments were measured with the caliper and flexible measuring tape, respectively. Additionally, the structural dimensions of head and foot (Figs. 6 and 7) were also obtained by the above-mentioned measuring process. The definitions of all the dimensions are described in detail in Online Appendix 1. All the measurements were executed by 2 well-trained examiners who are familiar with the anatomical structures of human body. 
Fig. 4 Positions and available dimensions of hand
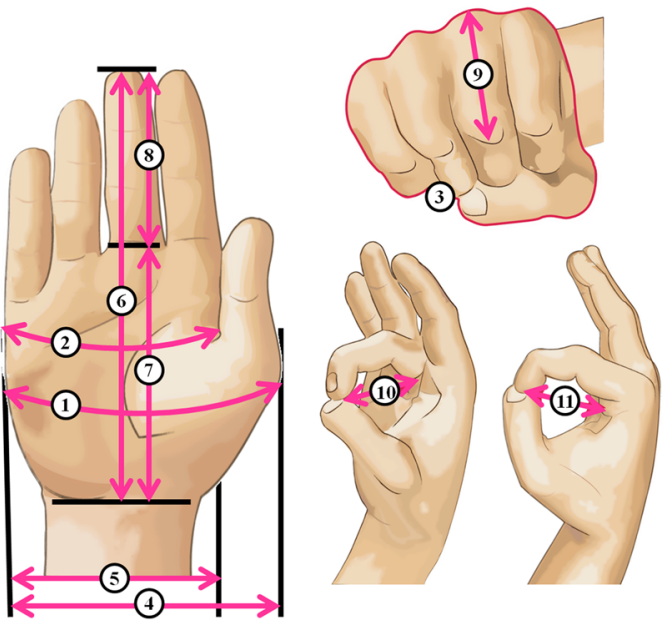

1. Hand circumference including thumb

2. Hand circumference

3. Fist circumference

4. Hand breadth across thumb

5. Hand breadth

6. Hand length

7. Palm length

8. Middle finger length

9. Proximal phalanx length of middle finer 10.Grip diameter, inside, index finger

11. Grip diameter, inside, middle finger

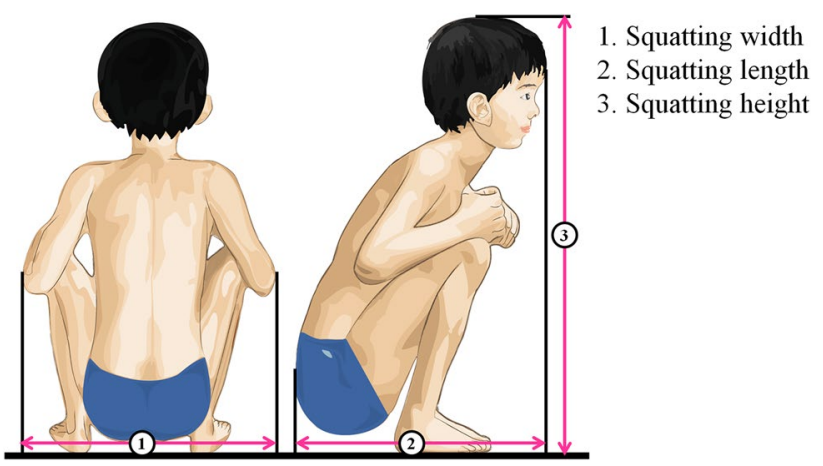

Fig. 5 Positions and available dimensions in squatting
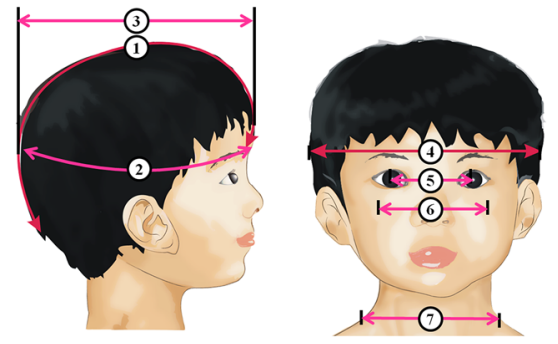

1. Sagittal arc

2. Head circumference

3. Head length

4. Head breadth

5. Interpupillary breadth

6. Face breadth

7. Neck breadth

Fig. 6 Structural dimensions of head

\subsection{Anthropometry}

The anthropometric parameters in the present study were divided into three categories: (1) basic data: stature, weight and Body Mass Index (BMI); (2) structural dimensions: the segmental dimensions of head-neck, trunk, upper extremity, hand, lower extremity and foot; (3) postural dimensions: the relative spacial dimensions when standing, sitting and squatting (see Online Appendix for more details).
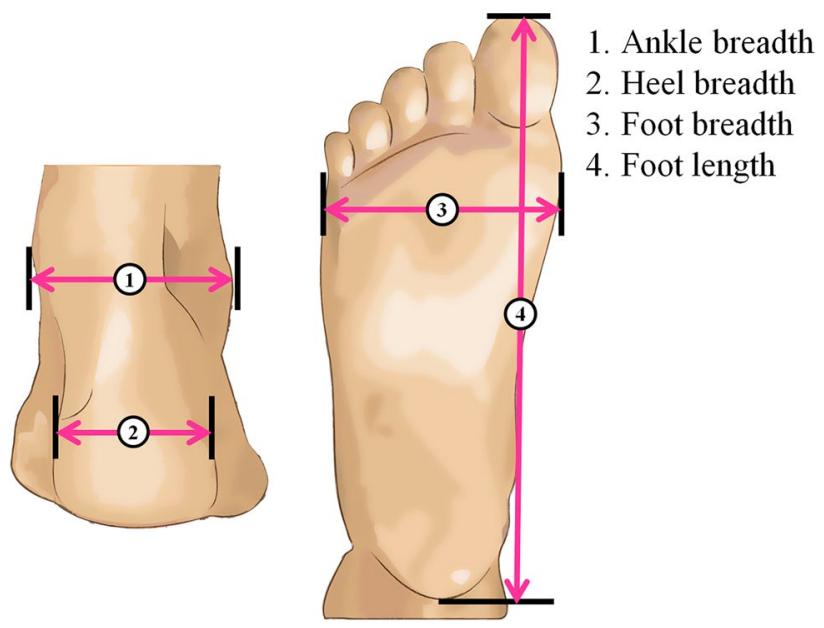

Fig. 7 Structural dimensions of foot

\subsection{Data Analysis}

In the preliminary process, intraclass correlation coefficient (ICC) was used to test reliability in repeated measurements by the same examiner (intra-rater) and between measurements carried out by two examiners (inter-rater) in the data obtained from flexible measuring tape, electronic caliper and 3SPACE FASTRAK. Besides, $t$ test was also used to examine if there is any significant differences between two groups of children living in city and country.

Descriptive statistics were used to examine the data, and the means, standard deviations (SD) and the percentiles of the 5th, 50th and 95th were obtained for the boys and girls at different ages. The basic anthropometric data, such as stature and weight of children in the United States (Centers for Disease Control and Prevention) and Japan (Ministry of Health, Labour and Welfare) were then compared with the corresponding anthropometric data of Taiwanese children gathered in this study. 
Table 1 The basic anthropometric data of children in Taiwan ( $\mathrm{N}$ is for sample size)

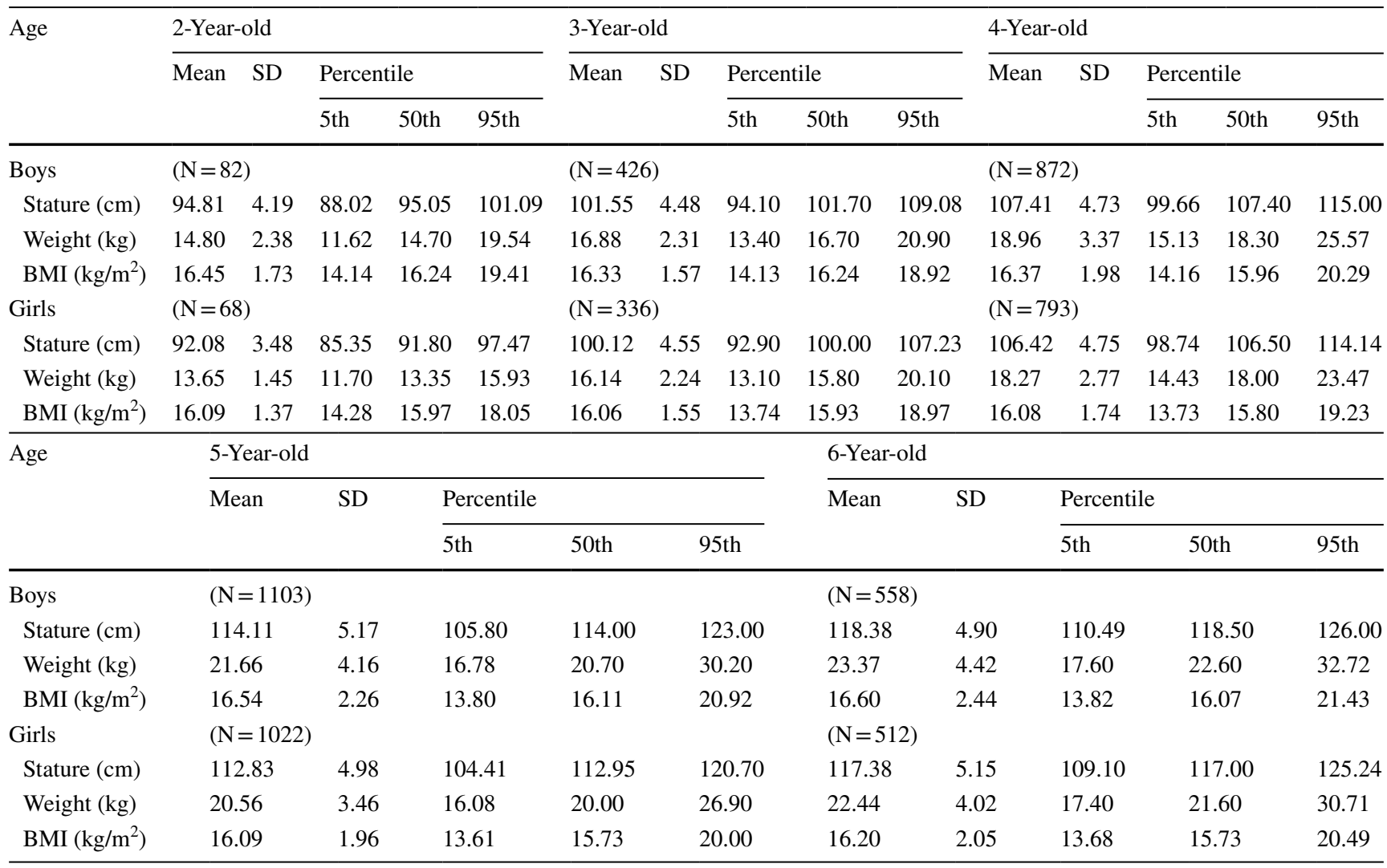

\section{Results}

The results of ICC display a value of 0.998 in repeated measurements by the same examiner in different times as well as a value of 0.998 between measurements by different examiners. It demonstrated both high intra-rater reliability and high inter-rater reliability. In the preliminary data analysis of first 1593 participants, the result shows no significant difference with $p$ values more than 0.05 in all anthropometric and dimensional values between children living in city and in country. Therefore, the data of children living in city and country are pooled together for analysis.

Descriptive statistics of the means, standard deviations (SD) and the 5th, 50th and 95th percentiles of each group were calculated, results were then further separated into those for boys and girls at different ages. The basic anthropometric values are shown in Table 1, including stature, weight and BMI. Figure 8 illustrates the stature and weight values among children in Taiwan, Japan (Ministry of Health, Labour and Welfare, Japan) and the United States (Centers for Disease Control and Prevention, USA). Although further statistical comparisons could not be conducted due to deficiency of raw data of children of Japan and the United States from previous studies, it was still able to tell some tendencies from comparisons of mean values of stature and weight of children in different countries. It reveals that Taiwanese children are generally taller than Japanese ones from 2 to 6 years old. Moreover, Taiwanese children under 5 years old are usually taller than those in the United States. However, after the age of five, children in the United States become taller than Taiwanese ones. Similar results were found for body weight, children in Taiwan weigh more than those in Japan. As for Taiwan and the United States, children aged over five in the latter weigh more than those in the former, consistent with the stature results.

Tables 2, 3, and 4 show the structural dimensions of headand-trunk, upper extremities and lower extremities, including lengths, breadths and circumferences. Table 5 shows the results of the postural dimensions in the standing, sitting, and squatting positions. Generally, the results for all the physical dimensions show stable growth from ages two to six. In addition, the results show that boys have slightly greater anthropometric values than girls in most of the physical dimensions, although these differences are not statistically significant.

\section{Discussion}

The results of the preliminary comparison of the stature and weights of children in Taiwan, Japan and the US indicates differences in the anthropometric dimensions of children 

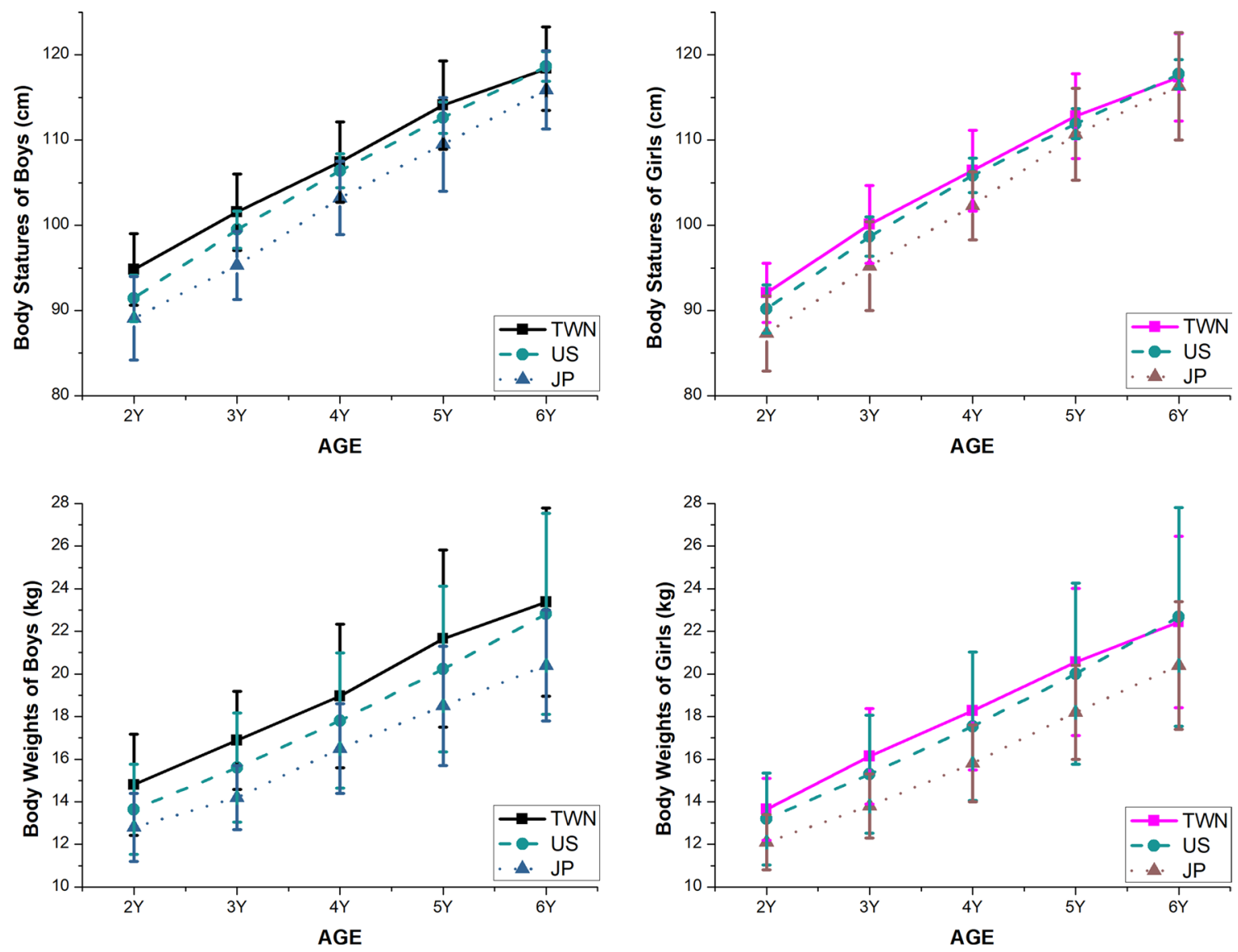

Fig. 8 Stature and weight values among children in Taiwan, Japan and USA

with different ethnicities. That is consistent with the statement of previous study in ethnic differences in adolescence [18] and adults. The differences found in this study could be examined in relation to other issues associated with the pediatric development of different races. It is also necessary to establish an anthropometric database for the specific ethnic population of each individual country, so that the living quality of its citizens can advance with more suitable and safer products and environmental design.

A spot survey in Taiwan found seat heights of $24-27 \mathrm{~cm}$ and toilet heights of $28-31 \mathrm{~cm}$ were common in kindergartens, with a single size generally used for all the children of different ages using the facilities. However, a single size is very inappropriate for all preschool children, because the body grows very rapidly from two to six. Comparing the values for popliteal height obtained in this study, it can be supposed that the current chairs and toilets used in the kindergartens in Taiwan are suitable only for the children older than four (with a popliteal height of $25-27 \mathrm{~cm}$ ). The oversized chairs and toilets now used are thus a potential hazard for the younger preschoolers, and it is recommended that there should be chairs and toilets with different sizes in kindergartens, since desks and chairs of different sizes are commonly available for children in elementary schools in Taiwan.

Playgrounds can be dangerous places where injuries often occur, particularly when the environment is not so welldesigned. Falls are most common accidents [23], and these usually result from the improper height of equipment or improper diameter of the hand supports provided [24]. The inside grip diameters found in this study could be used as a reference when designing the handrail diameters of playground equipment. As to protective equipment, the interval between two longitudinal bars of a stockade, for example, should not be less than the head breadth of a child, which is suggested not wider than $14 \mathrm{~cm}$ for preschool children in Taiwan. Younger children are more likely to be injured when playing in a playground [25], because they fail to judge distances very well, and also lack good motor control and adequate muscle strength. Impacts are also a common cause of injuries in playgrounds, and these occur more easily when the space allowed for movement is insufficient. For example, heads or elbows may hit the walls when moving through a narrow tunnel. Since playing is very important for 
Table 2 Head-and-trunk: the structural dimensions of children in Taiwan ( $\mathrm{N}$ is for sample size; unit: $\mathrm{cm}$ )

\begin{tabular}{|c|c|c|c|c|c|c|c|c|c|c|c|c|c|c|c|}
\hline \multirow[t]{3}{*}{ Age } & \multicolumn{5}{|c|}{ 2-Year-old } & \multicolumn{5}{|c|}{ 3-Year-old } & \multicolumn{5}{|c|}{ 4-Year-old } \\
\hline & \multirow[t]{2}{*}{ Mean } & \multirow[t]{2}{*}{ SD } & \multicolumn{3}{|c|}{ Percentile } & \multirow[t]{2}{*}{ Mean } & \multirow[t]{2}{*}{ SD } & \multicolumn{3}{|c|}{ Percentile } & \multirow[t]{2}{*}{ Mean } & \multirow[t]{2}{*}{ SD } & \multicolumn{3}{|c|}{ Percentile } \\
\hline & & & 5 th & 50 th & 95th & & & 5 th & 50 th & 95th & & & 5 th & 50 th & 95 th \\
\hline Boys & \multicolumn{5}{|c|}{$(\mathrm{N}=82)$} & \multicolumn{5}{|c|}{$(\mathrm{N}=426)$} & \multicolumn{5}{|c|}{$(\mathrm{N}=872)$} \\
\hline Sagittal arc & 28.91 & 1.62 & 26.34 & 29.00 & 31.50 & 29.06 & 1.65 & 26.50 & 29.00 & 32.00 & 29.22 & 1.75 & 26.61 & 29.00 & 32.50 \\
\hline Head circumference & 49.36 & 1.33 & 47.31 & 49.50 & 51.29 & 50.10 & 1.46 & 47.73 & 50.00 & 52.58 & 50.73 & 1.35 & 48.50 & 50.70 & 53.00 \\
\hline Head length & 15.88 & 0.78 & 14.56 & 15.91 & 17.04 & 16.29 & 0.99 & 14.86 & 16.20 & 18.02 & 16.54 & 1.20 & 14.96 & 16.41 & 18.89 \\
\hline Head breadth & 14.39 & 0.64 & 13.33 & 14.47 & 15.22 & 14.49 & 0.67 & 13.37 & 14.49 & 15.53 & 14.72 & 0.71 & 13.51 & 14.72 & 15.83 \\
\hline Interpupillary breadth & 4.18 & 0.58 & 3.34 & 4.08 & 5.37 & 4.39 & 0.58 & 3.62 & 4.31 & 5.51 & 4.57 & 0.53 & 3.78 & 4.52 & 5.52 \\
\hline Face breadth & 9.71 & 1.04 & 7.80 & 9.94 & 11.08 & 9.66 & 1.05 & 7.93 & 9.61 & 11.39 & 9.50 & 1.02 & 7.82 & 9.46 & 11.16 \\
\hline Neck breadth & 8.32 & 0.74 & 7.30 & 8.28 & 9.70 & 8.46 & 0.75 & 7.30 & 8.46 & 9.77 & 8.57 & 0.87 & 7.26 & 8.51 & 10.08 \\
\hline Chest circumference & 51.00 & 3.39 & 46.51 & 50.85 & 56.20 & 53.37 & 3.05 & 49.00 & 53.00 & 58.80 & 55.07 & 3.54 & 50.50 & 54.50 & 61.67 \\
\hline Bust depth & 14.66 & 1.22 & 12.78 & 14.58 & 16.86 & 13.51 & 1.08 & 11.93 & 13.43 & 15.22 & 14.18 & 1.20 & 12.51 & 14.09 & 16.30 \\
\hline Biacromial breadth & 21.12 & 1.31 & 18.93 & 21.06 & 23.33 & 22.45 & 1.33 & 20.33 & 22.45 & 24.64 & 23.46 & 1.49 & 21.15 & 23.51 & 25.92 \\
\hline Interscye & 17.06 & 1.65 & 14.82 & 16.80 & 19.71 & 18.37 & 1.88 & 15.77 & 18.12 & 22.11 & 19.65 & 2.07 & 16.58 & 19.43 & 23.32 \\
\hline Girls & \multicolumn{5}{|c|}{$(\mathrm{N}=68)$} & $(\mathrm{N}=33$ & & & & & $(\mathrm{N}=7 \mathrm{C}$ & 93) & & & \\
\hline Sagittal arc & 28.09 & 1.74 & 25.70 & 28.00 & 31.21 & 28.57 & 1.66 & 26.00 & 28.50 & 31.35 & 28.68 & 1.85 & 26.00 & 28.50 & 32.15 \\
\hline Head circumference & 48.60 & 1.24 & 46.80 & 48.70 & 50.33 & 49.12 & 1.35 & 47.00 & 49.00 & 51.30 & 49.82 & 1.46 & 47.50 & 49.80 & 52.20 \\
\hline Head length & 15.78 & 0.84 & 14.35 & 15.92 & 17.03 & 16.02 & 1.06 & 14.61 & 15.88 & 17.97 & 16.47 & 1.30 & 14.65 & 16.32 & 18.98 \\
\hline Head breadth & 14.02 & 0.55 & 13.07 & 14.06 & 14.94 & 14.17 & 0.62 & 13.22 & 14.17 & 15.12 & 14.36 & 0.63 & 13.31 & 14.36 & 15.34 \\
\hline Interpupillary breadth & 3.98 & 0.51 & 3.42 & 3.86 & 4.94 & 4.24 & 0.56 & 3.48 & 4.16 & 5.30 & 4.46 & 0.55 & 3.64 & 4.40 & 5.43 \\
\hline Face breadth & 9.45 & 1.00 & 7.62 & 9.42 & 11.08 & 9.46 & 1.04 & 7.75 & 9.46 & 11.10 & 9.29 & 1.05 & 7.44 & 9.30 & 10.97 \\
\hline Neck breadth & 8.12 & 0.82 & 6.81 & 8.10 & 9.47 & 8.34 & 0.81 & 6.97 & 8.41 & 9.59 & 8.36 & 0.86 & 7.00 & 8.33 & 9.77 \\
\hline Chest circumference & 49.77 & 3.17 & 45.81 & 49.00 & 56.46 & 51.85 & 2.85 & 47.88 & 51.50 & 57.03 & 54.11 & 3.52 & 49.10 & 53.60 & 60.14 \\
\hline Bust depth & 12.62 & 1.26 & 11.29 & 12.48 & 14.55 & 13.17 & 1.03 & 11.69 & 13.05 & 15.04 & 13.76 & 1.15 & 12.14 & 13.62 & 15.75 \\
\hline Biacromial breadth & 20.93 & 1.07 & 19.28 & 20.83 & 22.83 & 22.07 & 1.23 & 20.06 & 22.01 & 24.27 & 23.18 & 1.49 & 20.62 & 23.20 & 25.60 \\
\hline Interscye & 16.98 & 1.40 & 15.39 & 16.72 & 19.68 & 18.37 & 1.88 & 15.71 & 18.16 & 21.80 & 19.45 & 2.15 & 16.28 & 19.26 & 23.30 \\
\hline Age & & ear-old & & & & & & & 6-Yea & -old & & & & & \\
\hline & $\mathrm{Me}$ & & SD & & centile & & & & Mean & S & & Percent & & & \\
\hline & & & & 5 th & & 50 th & 95 & th & & & & 5 th & $50 \mathrm{t}$ & & 95th \\
\hline Boys & & $=1103)$ & & & & & & & $(\mathrm{N}=5$ & & & & & & \\
\hline Sagittal arc & 29 & & 1.75 & 27 & & 29.40 & & 2.80 & 29.55 & & 63 & 27.00 & 29. & .50 & 32.50 \\
\hline Head circumference & 51 & & 1.41 & 49 & & 51.10 & & 3.60 & 51.51 & & 45 & 49.00 & 51. & .50 & 53.80 \\
\hline Head length & 16 & & 1.21 & 15 & & 16.41 & & 3.94 & 16.80 & & 31 & 15.07 & 16. & .57 & 19.38 \\
\hline Head breadth & 14 & & 0.62 & 13 & & 14.92 & & 5.93 & 15.06 & & 64 & 14.01 & 15 . & .08 & 16.07 \\
\hline Interpupillary breadth & 4.6 & & 0.55 & 3.8 & & 4.65 & 5. & 63 & 4.69 & & 56 & 3.77 & 4.6 & & 5.55 \\
\hline Face breadth & 9.7 & & 0.97 & 8.1 & & 9.71 & & 1.31 & 10.03 & & 96 & 8.50 & 10. & .04 & 11.72 \\
\hline Neck breadth & 8.8 & & 0.87 & 7.5 & & 8.84 & & 0.39 & 9.04 & & 87 & 7.73 & 8.9 & & 10.70 \\
\hline Chest circumference & 57 & 47 & 4.43 & 51 & 70 & 56.70 & & 5.31 & 58.84 & & 51 & 53.00 & 58. & .00 & 68.00 \\
\hline Bust depth & 14 & 64 & 1.29 & 12 & 76 & 14.53 & & 7.02 & 15.01 & & 28 & 13.13 & 14. & 92 & 17.28 \\
\hline Biacromial breadth & 24 & 75 & 1.60 & 22 & & 24.77 & & 7.40 & 25.51 & & 61 & 22.86 & 25 . & .48 & 28.30 \\
\hline Interscye & 20 & & 2.31 & 17 & & 20.28 & & 4.78 & 21.02 & & 47 & 17.50 & 20. & .64 & 25.55 \\
\hline Girls & & $=1022)$ & & & & & & & $(\mathrm{N}=5$ & & & & & & \\
\hline Sagittal arc & 28 & 87 & 1.79 & 26 & & 28.70 & & 2.00 & 29.00 & & 58 & 26.50 & 29. & .00 & 32.00 \\
\hline Head circumference & 50 & 31 & 1.44 & 48 & & 50.30 & & 2.60 & 50.66 & & 49 & 48.50 & 50. & 60 & 53.15 \\
\hline Head length & 16 & 79 & 1.53 & 14 & & 16.51 & & 9.77 & 16.87 & & 51 & 14.98 & 16. & .48 & 19.83 \\
\hline Head breadth & 14 & 58 & 0.61 & 13 & & 14.58 & & 5.61 & 14.72 & & 59 & 13.77 & 14 & .71 & 15.70 \\
\hline Interpupillary breadth & 4.5 & & 0.54 & 3.7 & & 4.54 & 5. & 53 & 4.61 & & 52 & 3.78 & 4.6 & & 5.49 \\
\hline Face breadth & 9.5 & & 1.00 & 7.8 & & 9.54 & & 1.07 & 9.93 & & 93 & 8.47 & 9.9 & & 11.35 \\
\hline
\end{tabular}


Table 2 (continued)

\begin{tabular}{|c|c|c|c|c|c|c|c|c|c|c|}
\hline \multirow[t]{3}{*}{ Age } & \multicolumn{5}{|c|}{ 5-Year-old } & \multicolumn{5}{|c|}{ 6-Year-old } \\
\hline & \multirow[t]{2}{*}{ Mean } & \multirow[t]{2}{*}{ SD } & \multicolumn{3}{|c|}{ Percentile } & \multirow{2}{*}{ Mean } & \multirow[t]{2}{*}{ SD } & \multicolumn{3}{|c|}{ Percentile } \\
\hline & & & 5 th & 50 th & 95 th & & & 5 th & 50 th & 95 th \\
\hline Neck breadth & 8.61 & 0.89 & 7.28 & 8.53 & 10.19 & 8.87 & 0.90 & 7.57 & 8.75 & 10.43 \\
\hline Chest circumference & 55.96 & 3.97 & 50.70 & 55.50 & 63.30 & 57.29 & 4.14 & 51.50 & 56.60 & 65.05 \\
\hline Bust depth & 14.24 & 1.22 & 12.49 & 14.14 & 16.47 & 14.66 & 1.22 & 12.78 & 14.58 & 16.86 \\
\hline Biacromial breadth & 24.31 & 1.49 & 21.86 & 24.32 & 26.65 & 25.15 & 1.50 & 22.92 & 25.08 & 27.66 \\
\hline Interscye & 20.36 & 2.24 & 16.97 & 20.12 & 24.35 & 20.67 & 2.16 & 17.42 & 20.46 & 24.38 \\
\hline
\end{tabular}

the development of children in motor control learning, safe environments to play within should be provided for children in order to minimize the risk of injury.

The anthropometric values obtained in this study can provide a reliable reference for Taiwanese preschool children, so that the products or environment designed for them can be made in more appropriate sizes. With regard to the application of anthropometric values, primarily, the dimensions of products should be selected based on the anthropometric values and the functional properties of the products. The appropriate values also depend on the designer's expectations and the users' properties. The means of the anthropometric values are not always suitable for use, and designers should consider both the maximum and minimum values so that products can be more suitable for more users. The 5 th and the 95th percentiles are generally used as a reference range when designing for the majority population on the basis of the principle of designing for an adjustable range $[26,27]$. For this reason, not only the means but also the 5th and the 95th percentiles of each dimension measurement are given in this work to provide a more useful anthropometric database for preschool children in Taiwan. Although the anthropometric database established in this study is based on Taiwanese preschool children, this reliable and largescale anthropometric database can also be used as a valuable reference for other ethnically Chinese children of the same age living in Asia. The principles for the application of this anthropometric data are the same in the design and manufacturing of equipment for children, and it is anticipated that the data gathered in this work will help to focus attention on the issue of preschool children's ergonomics in Asia.

The techniques of body measuring are advancing continuously. In this study, an electromagnetic motion analysis system, flexible measuring tapes and electronic calipers were used for body dimension measuring. Although 3D body scanners are regarded as the most precise and rapid measuring tools, vast majority of individuals in the related research or industrial application are adults or older than 16 years old [28-31]. 3D body scanner are commonly used to measure local dimensions of heads, hands or feet, as well as circumference of segments because they are simple and quick [32, 33].
However, the measuring time is $10 \mathrm{~s}$ or longer for whole body scanning and any event of body movements are not allowed. Moreover, subjects must be scanned in a specific space by themselves. It is a great challenge for a preschool child to stay still in a certain pose all alone even for several seconds. In a few studies about 3D body measuring for children, all the participants are older than 3 years who are developmental maturity sufficient to stand still for whole body scanning [34-37]. Age limitation and applicability of measuring tools should be carefully selected in body dimension measuring of young children. Admittedly, measuring of young children (2-3 years old) is a great challenge because of the instability. The measuring tools of this study are assembled and portable so that measurements could be carried out in the kindergartens around Taiwan for the preschool children. The examiners are with the subjects face to face all through the process of measuring to ease anxiety or fear of young children so that they would follow the instructions in their familiar place and with the examiners by their sides. Sometime, if children are too young to understand the oral instruction, body language or assistance from the teachers of their kindergartens are necessary.

When it comes to practical applications of human anthropometry in design work, the database produced in this study seems to be rather insufficient, particularly for equipment that is related to dynamic movements, such as that used for climbing. The database established in this study only involves static human anthropometry, and is not completely appropriate to be applied in dynamic-related products. A larger and more comprehensive anthropometric database including dynamic human anthropometry of Taiwanese preschool children should be developed and integrated in the future.

\section{Conclusion}

Anthropometric data from Western children has been applied to a Taiwanese context for a long time, despite the known ethnic differences in body size. However, due to regional and ethnic variances, it would be worthy to have 


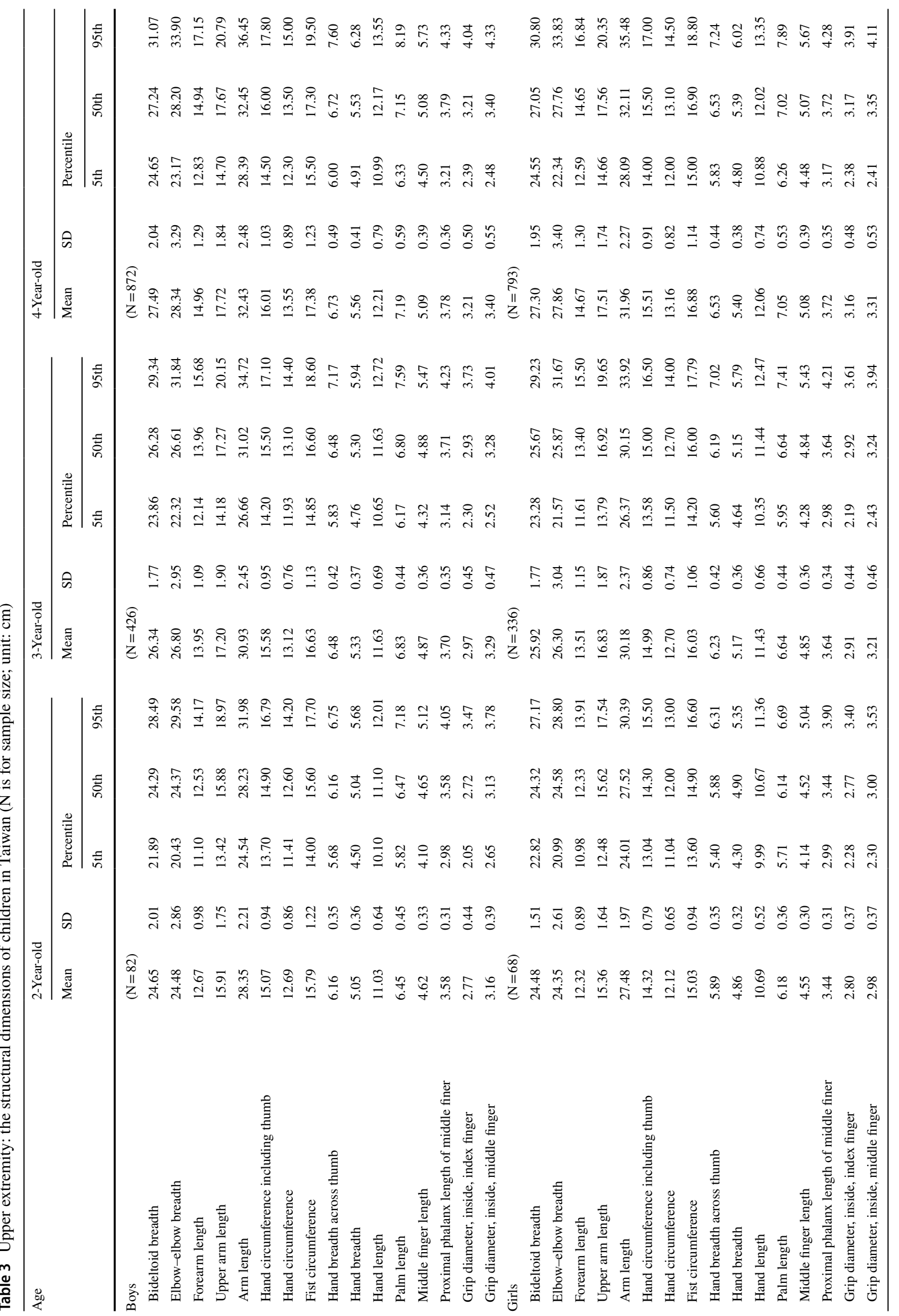




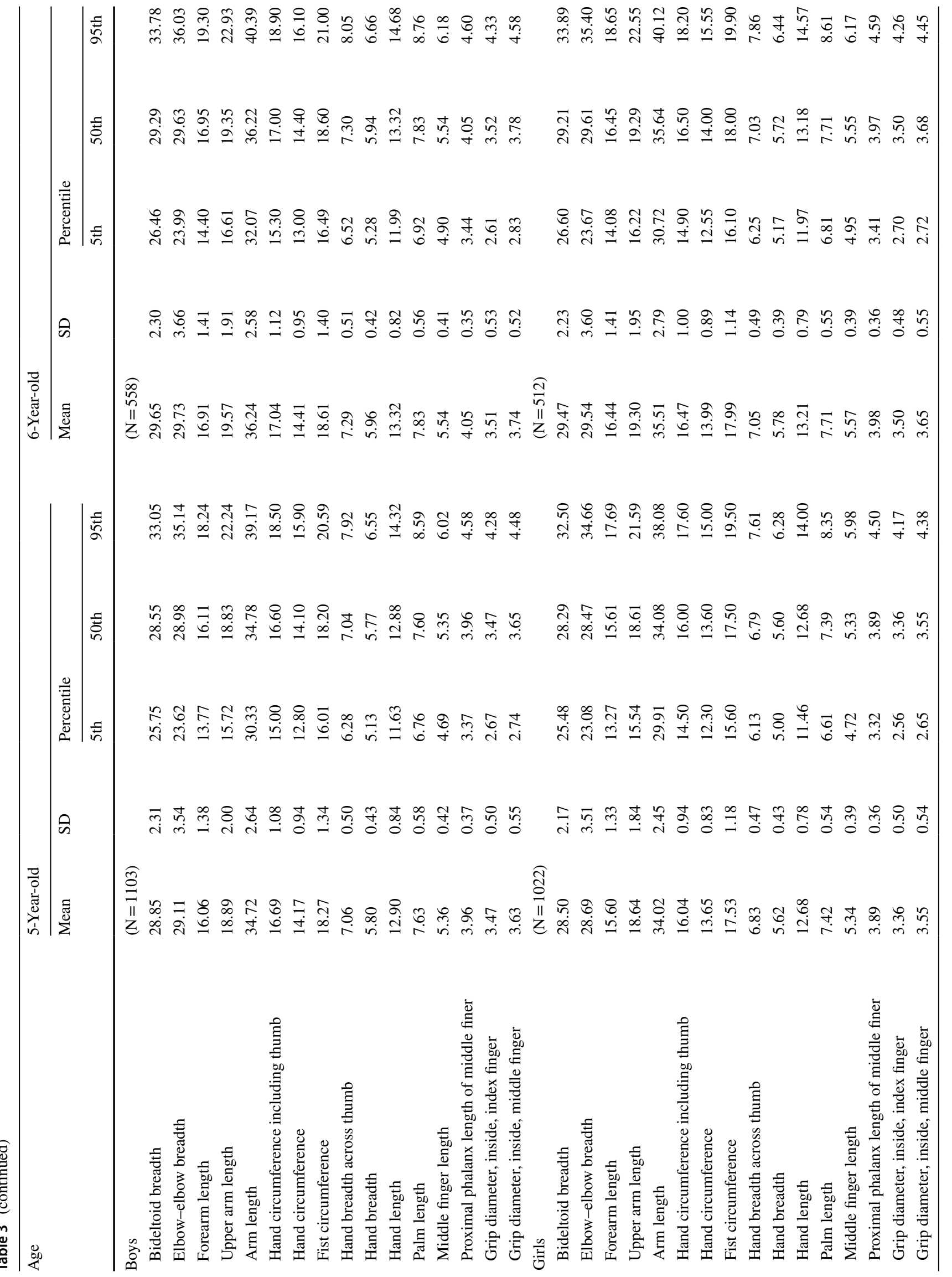


Table 4 Lower extremity: the structural dimensions of children in Taiwan ( $\mathrm{N}$ is for sample size; unit: $\mathrm{cm}$ )

\begin{tabular}{|c|c|c|c|c|c|c|c|c|c|c|c|c|c|c|c|}
\hline \multirow[t]{3}{*}{ Age } & \multicolumn{5}{|c|}{ 2-Year-old } & \multicolumn{5}{|c|}{ 3-Year-old } & \multicolumn{5}{|c|}{ 4-Year-old } \\
\hline & \multirow[t]{2}{*}{ Mean } & \multirow[t]{2}{*}{ SD } & \multicolumn{3}{|c|}{ Percentile } & \multirow[t]{2}{*}{ Mean } & \multirow[t]{2}{*}{ SD } & \multicolumn{3}{|c|}{ Percentile } & \multirow[t]{2}{*}{ Mean } & \multirow[t]{2}{*}{ SD } & \multicolumn{3}{|c|}{ Percentile } \\
\hline & & & 5 th & 50th & 95th & & & 5 th & 50th & 95 th & & & 5 th & 50 th & 95th \\
\hline Boys & \multicolumn{5}{|c|}{$(\mathrm{N}=82)$} & $(\mathrm{N}=42$ & & & & & $(\mathrm{N}=87$ & & & & \\
\hline Thigh circumference & 29.25 & 3.61 & 24.20 & 28.60 & 35.29 & 31.16 & 3.20 & 26.50 & 30.75 & 36.88 & 32.56 & 4.04 & 27.30 & 32.00 & 40.20 \\
\hline Calf circumference & 20.77 & 1.78 & 18.12 & 20.50 & 23.80 & 21.78 & 1.62 & 19.31 & 21.70 & 24.80 & 22.53 & 2.01 & 19.95 & 22.30 & 26.00 \\
\hline Hip breadth, standing & 18.66 & 1.35 & 17.10 & 18.29 & 21.43 & 19.41 & 1.29 & 17.39 & 19.33 & 21.65 & 20.29 & 1.57 & 18.12 & 20.11 & 23.10 \\
\hline Hip breadth, sitting & 20.56 & 1.82 & 17.93 & 20.26 & 23.58 & 21.32 & 1.83 & 18.63 & 21.16 & 24.72 & 22.22 & 1.98 & 19.46 & 21.91 & 25.77 \\
\hline Thigh-thigh breadth, sitting & 22.77 & 2.09 & 20.02 & 22.30 & 26.91 & 23.59 & 2.41 & 19.76 & 23.61 & 27.69 & 23.81 & 2.66 & 19.93 & 23.57 & 28.72 \\
\hline Knee-knee breadth, sitting & 22.61 & 2.92 & 17.58 & 22.78 & 26.92 & 23.69 & 3.50 & 18.16 & 23.82 & 29.25 & 23.73 & 3.78 & 18.26 & 23.49 & 30.31 \\
\hline Buttock-knee length, sitting & 28.34 & 1.63 & 25.75 & 28.27 & 31.15 & 30.96 & 1.80 & 28.09 & 30.88 & 34.16 & 33.23 & 2.14 & 30.13 & 33.05 & 36.86 \\
\hline Ankle breadth & 4.72 & 0.32 & 4.18 & 4.70 & 5.25 & 4.97 & 0.34 & 4.40 & 4.98 & 5.50 & 5.12 & 0.37 & 4.56 & 5.11 & 5.70 \\
\hline Heel breadth & 3.47 & 0.41 & 2.86 & 3.41 & 4.27 & 3.61 & 0.45 & 2.92 & 3.59 & 4.43 & 3.82 & 0.50 & 3.09 & 3.79 & 4.64 \\
\hline Foot breadth & 6.06 & 0.37 & 5.51 & 6.07 & 6.59 & 6.38 & 0.46 & 5.62 & 6.39 & 7.13 & 6.57 & 0.50 & 5.83 & 6.54 & 7.39 \\
\hline Foot length & 14.54 & 1.10 & 12.89 & 14.58 & 16.18 & 15.44 & 0.89 & 13.97 & 15.40 & 16.87 & 16.35 & 1.02 & 14.73 & 16.37 & 18.09 \\
\hline Girls & $(\mathrm{N}=68$ & & & & & $(\mathrm{N}=33$ & & & & & $(\mathrm{N}=7 \mathrm{c}$ & & & & \\
\hline Thigh circumference & 29.26 & 2.91 & 25.17 & 29.00 & 34.70 & 30.43 & 3.00 & 26.00 & 30.20 & 35.53 & 32.25 & 3.61 & 27.26 & 31.90 & 38.50 \\
\hline Calf circumference & 20.37 & 1.26 & 18.51 & 20.35 & 22.50 & 21.62 & 1.57 & 19.40 & 21.50 & 24.20 & 22.46 & 1.72 & 19.90 & 22.30 & 25.50 \\
\hline Hip breadth, standing & 18.35 & 1.24 & 16.53 & 18.29 & 20.46 & 19.19 & 1.31 & 17.22 & 19.16 & 21.27 & 20.30 & 1.49 & 18.06 & 20.23 & 22.73 \\
\hline Hip breadth, sitting & 20.28 & 1.40 & 18.41 & 20.06 & 22.93 & 21.06 & 1.72 & 18.54 & 20.93 & 24.04 & 21.99 & 1.82 & 19.32 & 21.87 & 25.28 \\
\hline Thigh-thigh breadth, sitting & 22.43 & 2.41 & 18.45 & 22.36 & 26.09 & 22.30 & 2.60 & 18.46 & 21.94 & 26.75 & 22.63 & 2.66 & 18.43 & 22.31 & 27.42 \\
\hline Knee-knee breadth, sitting & 22.62 & 2.58 & 18.17 & 22.60 & 26.70 & 21.59 & 3.51 & 16.01 & 21.45 & 27.88 & 21.48 & 3.82 & 15.85 & 21.01 & 28.52 \\
\hline Buttock-knee length, sitting & 28.02 & 1.30 & 26.02 & 27.96 & 29.85 & 31.01 & 1.87 & 28.08 & 30.95 & 34.30 & 33.40 & 2.10 & 30.26 & 33.27 & 37.14 \\
\hline Ankle breadth & 4.55 & 0.32 & 4.04 & 4.55 & 4.97 & 4.74 & 0.33 & 4.21 & 4.75 & 5.29 & 4.98 & 0.36 & 4.40 & 4.98 & 5.54 \\
\hline Heel breadth & 3.35 & 0.39 & 2.82 & 3.30 & 3.93 & 3.53 & 0.44 & 2.89 & 3.46 & 4.33 & 3.76 & 0.46 & 3.10 & 3.72 & 4.58 \\
\hline Foot breadth & 5.87 & 0.37 & 5.36 & 5.79 & 6.51 & 6.18 & 0.48 & 5.50 & 6.17 & 6.94 & 6.42 & 0.49 & 5.64 & 6.41 & 7.24 \\
\hline Foot length & 13.93 & 0.68 & 12.99 & 13.87 & 15.24 & 15.18 & 0.95 & 13.71 & 15.16 & 16.87 & 16.12 & 1.00 & 14.38 & 16.18 & 17.72 \\
\hline Age & & ear-old & & & & & & & 6-Year & & & & & & \\
\hline & & & SD & & centile & & & & Mean & & SD & Percen & & & \\
\hline & & & & $5 \mathrm{t}$ & & 50 th & & & & & & 5 th & 50 & & 95 th \\
\hline Boys & & $=1103)$ & & & & & & & $(\mathrm{N}=5$ & & & & & & \\
\hline Thigh circumference & & & 4.72 & & & 33.50 & & .31 & 35.03 & & 4.24 & 29.60 & & & 43.22 \\
\hline Calf circumference & & & 2.24 & & & 23.20 & & .70 & 24.28 & & 2.28 & 21.00 & & & 28.90 \\
\hline Hip breadth, standing & & & 1.82 & & & 21.18 & & .76 & 22.13 & & 1.87 & 19.63 & & & 25.76 \\
\hline Hip breadth, sitting & & & 2.23 & & & 23.00 & & .73 & 24.15 & & 2.32 & 20.99 & & & 28.53 \\
\hline Thigh-thigh breadth, sitting & & & 3.14 & & & 24.63 & & .95 & 25.44 & & 3.32 & 20.19 & & & 30.93 \\
\hline Knee-knee breadth, sitting & & & 4.32 & & & 24.47 & & 64 & 25.19 & & 4.46 & 18.20 & & & 31.96 \\
\hline Buttock-knee length, sitting & & & 2.40 & & & 35.90 & & .02 & 37.80 & & 2.35 & 34.12 & & & 41.71 \\
\hline Ankle breadth & 5 . & & 0.39 & $4 .^{\prime}$ & & 5.39 & & & 5.54 & & 0.41 & 4.88 & 5. & & 6.22 \\
\hline Heel breadth & 4. & & 0.54 & 3.2 & & 3.99 & & & 4.08 & & 0.54 & 3.27 & 4. & & 4.95 \\
\hline Foot breadth & 6. & & 0.52 & 6. & & 6.92 & & & 7.11 & & 0.53 & 6.22 & 7. & & 7.96 \\
\hline Foot length & & & 1.14 & & & 17.37 & & .14 & 17.89 & & 1.06 & 16.28 & & & 19.67 \\
\hline Girls & & $=1022)$ & & & & & & & $(\mathrm{N}=5$ & & & & & & \\
\hline Thigh circumference & & & 4.06 & & & 33.00 & & .81 & 34.76 & & 4.20 & 28.86 & & & 42.68 \\
\hline Calf circumference & & & 1.99 & & & 23.20 & & 80 & 24.05 & & 2.12 & 21.05 & & & 28.10 \\
\hline Hip breadth, standing & & & 1.60 & & & 21.10 & & .01 & 22.00 & & 1.72 & 19.57 & & & 25.17 \\
\hline Hip breadth, sitting & & & 1.96 & & & 22.74 & & .17 & 23.66 & & 2.04 & 20.80 & & & 27.45 \\
\hline Thigh-thigh breadth, sitting & & & 2.80 & & & 22.83 & & .91 & 23.11 & & 2.83 & 18.83 & & & 28.02 \\
\hline Knee-knee breadth, sitting & & & 4.00 & & & 21.16 & & 68 & 21.14 & & 3.92 & 15.13 & & & 28.08 \\
\hline Buttock-knee length, sitting & & & 2.36 & & & 35.89 & & .78 & 37.92 & & 2.31 & 34.21 & & & 41.69 \\
\hline Ankle breadth & 5 . & & 0.35 & 4. & & 5.21 & & & 5.39 & & 0.38 & 4.79 & 5. & & 6.03 \\
\hline Heel breadth & 3. & & 0.51 & 3. & & 3.87 & & & 3.97 & & 0.50 & 3.20 & 3. & & 4.84 \\
\hline Foot breadth & 6. & & 0.52 & 5. & & 6.72 & & & 6.97 & & 0.50 & 6.20 & 6. & & 7.81 \\
\hline Foot length & & & 1.04 & & & 16.99 & & .73 & 17.71 & & 1.09 & 15.98 & & & 19.42 \\
\hline
\end{tabular}




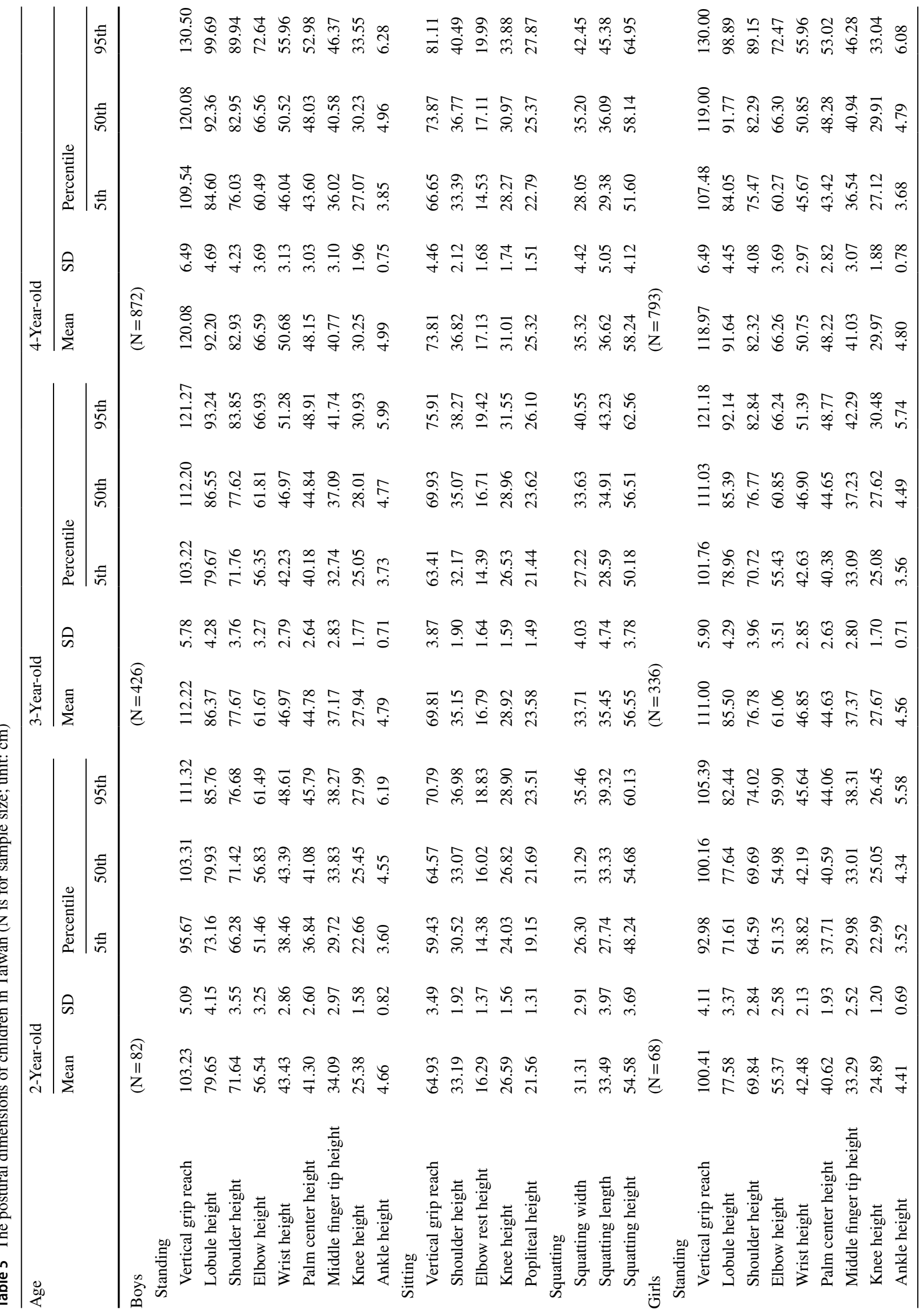




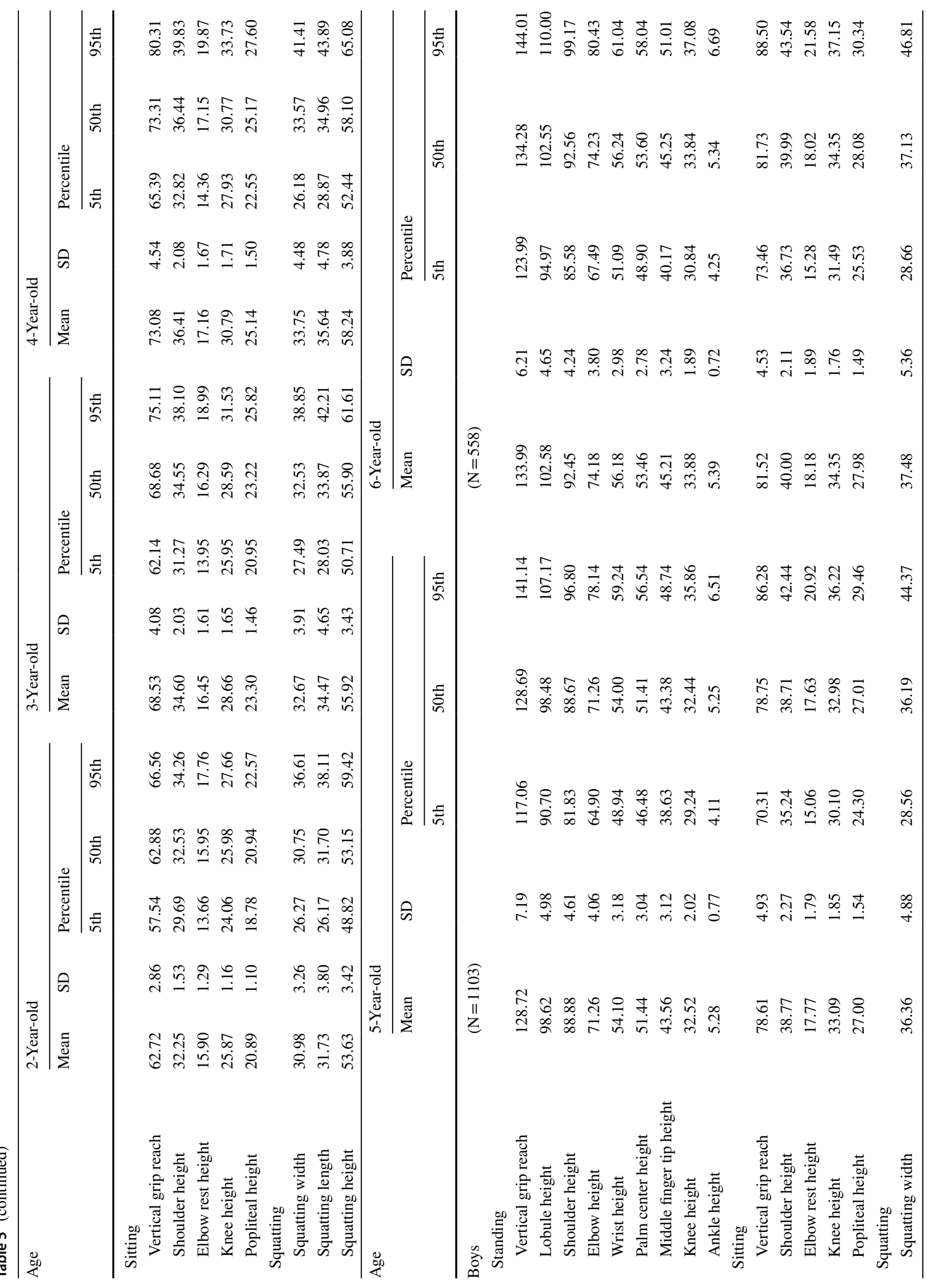




\begin{tabular}{|c|c|c|c|c|c|}
\hline & $\frac{5}{5}$ & 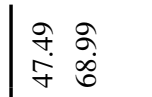 & 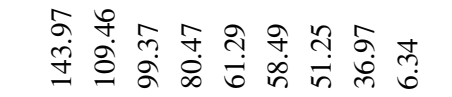 & 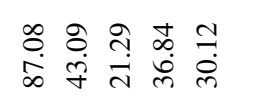 & 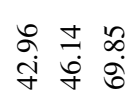 \\
\hline & 害 & $\underset{\substack{\infty \\
\infty}}{\stackrel{1}{\infty}}$ & 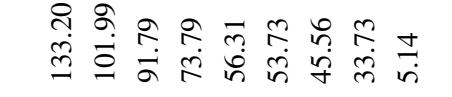 & 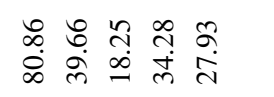 & 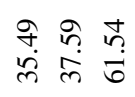 \\
\hline & 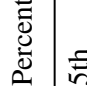 & 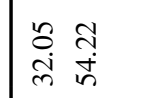 & 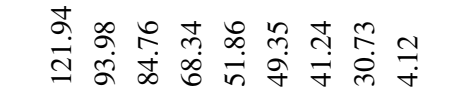 & 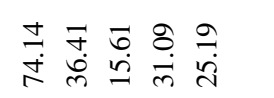 & 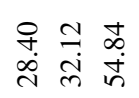 \\
\hline & हิ & 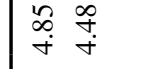 & 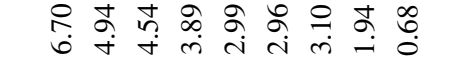 & 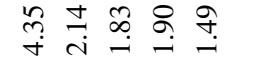 & 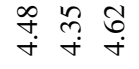 \\
\hline 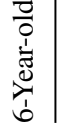 & $\sum_{\bar{c}}^{\approx}$ & 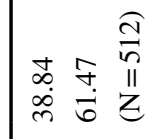 & 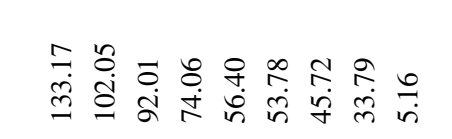 & 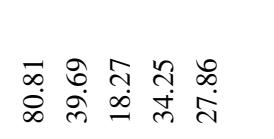 & 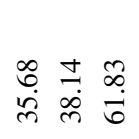 \\
\hline & $\frac{\bar{\nu}}{\Delta}$ & 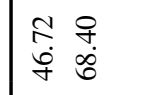 & 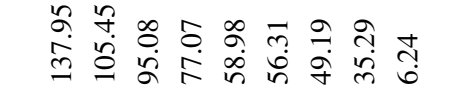 & 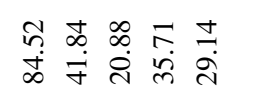 & $\begin{array}{lll}0 & \overrightarrow{0} & \circ \\
& \dot{\gamma} & \stackrel{8}{8}\end{array}$ \\
\hline & in & 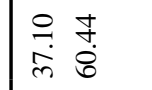 & 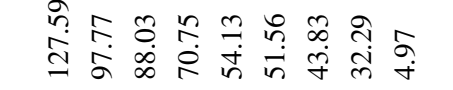 & 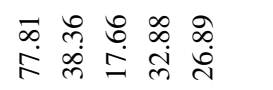 & 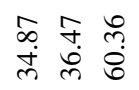 \\
\hline & 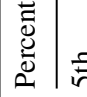 & 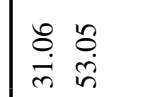 & 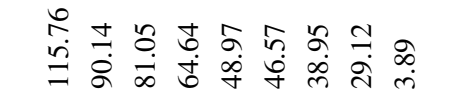 & 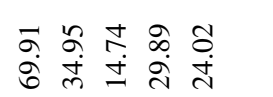 & 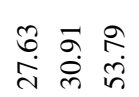 \\
\hline & 命 & $\begin{array}{ll}8 \\
\dot{n}\end{array}$ & 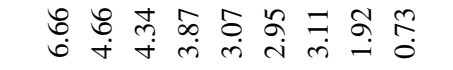 & 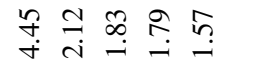 & 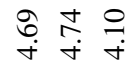 \\
\hline 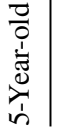 & $\sum^{\varpi ్}$ & 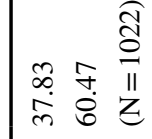 & 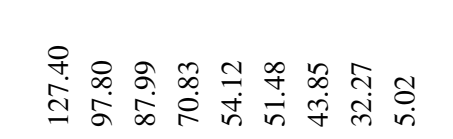 & 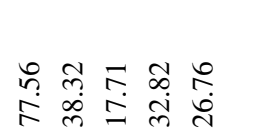 & 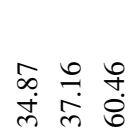 \\
\hline 8 & & 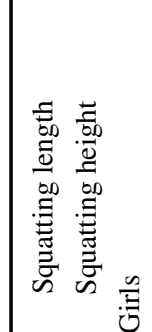 & 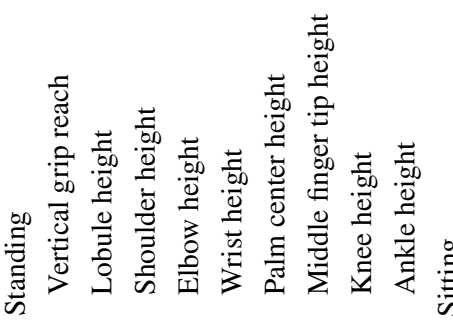 & 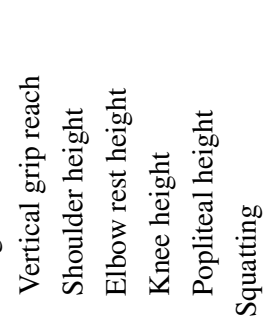 & 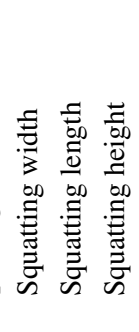 \\
\hline
\end{tabular}


anthropometric data of Taiwanese preschool children and to apply these data to related ergonomics design. A reliable large-scaled anthropometric database of preschool children in Taiwan was established in this study. It can serve as a useful and local reference for both designers and researchers, not only for child-related products or environments, but also for studies of other issues related to children, such as nutrition. In this way, the current work can help to increase the quality of life and safety of preschool children in Taiwan. Furthermore, by means of this study, it may be regarded as inspiration to other countries that anthropometry of children should be paid more attention to.

Acknowledgements This work was financially supported by the Medical Device Innovation Center, National Cheng Kung University from the Featured Areas Research Center Program within the framework of the Higher Education Sprout Project by the Ministry of Education (MOE) in Taiwan and was also partly supported by MOE Taiwan under Grant Number 96-187411. The authors also sincerely appreciate the teachers in the kindergartens and all the staffs involved in this study.

Open Access This article is distributed under the terms of the Creative Commons Attribution 4.0 International License (http://creativeco mmons.org/licenses/by/4.0/), which permits unrestricted use, distribution, and reproduction in any medium, provided you give appropriate credit to the original author(s) and the source, provide a link to the Creative Commons license, and indicate if changes were made.

\section{References}

1. Ayoub, M. A. (1990). Ergonomic deficiencies: I. Pain at work. Journal of Occupational Medicine, 32(1), 52-57.

2. Szeto, G. P., Straker, L., \& Raine, S. (2002). A field comparison of neck and shoulder postures in symptomatic and asymptomatic office workers. Applied Ergonomics, 33(1), 75-84.

3. Brewer, J. M., Davis, K. G., Dunning, K. K., \& Succop, P. A. (2009). Does ergonomic mismatch at school impact pain in school children? Work, 34(4), 455-464.

4. Saarni, L., Nygard, C. H., Kaukiainen, A., \& Rimpela, A. (2007). Are the desks and chairs at school appropriate? Ergonomics, 50(10), 1561-1570. https://doi.org/10.1080/00140130701587368.

5. Chung, J. W., \& Wong, T. K. (2007). Anthropometric evaluation for primary school furniture design. Ergonomics, 50(3), 323-334. https://doi.org/10.1080/00140130600842328.

6. Knight, G., \& Noyes, J. (1999). Children's behaviour and the design of school furniture. Ergonomics, 42(5), 747-760. https:// doi.org/10.1080/001401399185423.

7. Paschoarelli, L. C., \& da Silva, J. C. P. (2000). Ergonomic research applied in the design of pre-school furniture. Proceedings of the Human Factors and Ergonomics Society Annual Meeting, 44(8), 24-27.

8. Lu, C. W., \& Lu, J. M. (2017). Evaluation of the Indonesian National Standard for elementary school furniture based on children's anthropometry. Applied Ergonomics, 62, 168-181. https:// doi.org/10.1016/j.apergo.2017.03.004.

9. Trevelyan, F. C., \& Legg, S. J. (2011). Risk factors associated with back pain in New Zealand school children. Ergonomics, 54(3), 257-262. https://doi.org/10.1080/00140139.2010.547608.
10. Iyer, S. R. (2001). An ergonomic study of chronic musculoskeletal pain in schoolchildren. Indian Journal of Pediatrics, 68(10), 937-941.

11. Troussier, B., Tesniere, C., Fauconnier, J., Grison, J., Juvin, R., \& Phelip, X. (1999). Comparative study of two different kinds of school furniture among children. Ergonomics, 42(3), 516-526.

12. Marschall, M., Harrington, A. C., \& Steele, J. R. (1995). Effect of work station design on sitting posture in young children. Ergonomics, 38(9), 1932-1940. https://doi.org/10.1080/0014013950 8925241.

13. Morrison, L., Chalmers, D. J., Parry, M. L., \& Wright, C. S. (2002). Infant-furniture-related injuries among preschool children in New Zealand, 1987-1996. Journal of Paediatrics and Child Health, 38(6), 587-592.

14. Ulione, M. S., \& Dooling, M. (1997). Preschool injuries in child care centers: Nursing strategies for prevention. Journal of Pediatric Health Care, 11(3), 111-116.

15. Wagner, D. R., \& Heyward, V. H. (2000). Measures of body composition in blacks and whites: A comparative review. American Journal of Clinical Nutrition, 71(6), 1392-1402.

16. Deurenberg, P., Deurenberg-Yap, M., Foo, L. F., Schmidt, G., \& Wang, J. (2003). Differences in body composition between Singapore Chinese, Beijing Chinese and Dutch children. European Journal of Clinical Nutrition, 57(3), 405-409. https://doi. org/10.1038/sj.ejcn.16015691601569.

17. Kagawa, M., Binns, C. W., \& Hills, A. P. (2007). Body composition and anthropometry in Japanese and Australian Caucasian males and Japanese females. Asia Pacific Journal of Clinical Nutrition, 16, 31-36.

18. Sampei, M. A., Novo, N. F., Juliano, Y., \& Sigulem, D. M. (2008). Anthropometry and body composition in ethnic Japanese and Caucasian adolescent boys. Pediatrics International, 50(5), 679-686. https://doi.org/10.1111/j.1442-200X.2008.002633.x.

19. Lin, Y. C., Wang, M. J., \& Wang, E. M. (2004). The comparisons of anthropometric characteristics among four peoples in East Asia. Applied Ergonomics, 35(2), 173-178. https://doi.org/10.1016/j. apergo.2004.01.004S0003-6870(04)00017-1.

20. Agarwal, D. K., \& Agarwal, K. N. (1994). Physical growth in Indian affluent children (birth-6 years). Indian Pediatrics, 31(4), 377-413.

21. Wang, M. J., Wang, E. M., \& Lin, Y. C. (2002). The anthropometric database for children and young adults in Taiwan. Applied Ergonomics, 33(6), 583-585.

22. Lohman, T. G., \& Roche, A. F. (1988). Anthropometric standardization reference manual (Vol. 177). Champaign: Human Kinetics Books.

23. Bernardo, L. M., Gardner, M. J., \& Seibel, K. (2001). Playground injuries in children: A review and Pennsylvania Trauma Center experience. Journal of Pediatric Nursing, 6(1), 11-20.

24. Macarthur, C., Hu, X., Wesson, D. E., \& Parkin, P. C. (2000). Risk factors for severe injuries associated with falls from playground equipment. Accident Analysis and Prevention, 32(3), 377-382.

25. Norton, C., Nixon, J., \& Sibert, J. R. (2004). Playground injuries to children. Archives of Disease in Childhood, 89(2), 103-108.

26. Taifa, I. W., \& Desai, D. A. (2017). Anthropometric measurements for ergonomic design of students' furniture in India. Engineering Science and Technology, an International Journal, 20(1), 232-239. https://doi.org/10.1016/j.jestch.2016.08.004.

27. Khaspuri, G. C., Sau, S. K., \& Dhara, P. C. (2007). Anthropometric consideration for designing class room furniture in rural schools. Journal of Human Ecology, 22(3), 10.

28. Loffler-Wirth, H., Willscher, E., Ahnert, P., Wirkner, K., Engel, C., Loeffler, M., et al. (2016). Novel anthropometry based on 3D-bodyscans applied to a large population based cohort. PLOS ONE, 11(7), e0159887. https://doi.org/10.1371/journal.pone.0159887. 
29. Bretschneider, T., Koop, U., Schreiner, V., Wenck, H., \& Jaspers, S. (2009). Validation of the body scanner as a measuring tool for a rapid quantification of body shape. Skin Research and Technology, 15(3), 364-369. https://doi.org/10.1111/j.1600-0846.2009.00374 .x.

30. Lin, J. D., Chiou, W. K., Weng, H. F., Fang, J. T., \& Liu, T. H. (2004). Application of three-dimensional body scanner: Observation of prevalence of metabolic syndrome. Clinical Nutrition, 23(6), 1313-1323. https://doi.org/10.1016/j.clnu.2004.04.005.

31. Wells, J. C., Ruto, A., \& Treleaven, P. (2008). Whole-body threedimensional photonic scanning: A new technique for obesity research and clinical practice. International Journal of Obesity (London), 32(2), 232-238. https://doi.org/10.1038/sj.ijo.0803727.

32. Pepper, M. R., Freeland-Graves, J. H., Yu, W., Stanforth, P. R., Cahill, J. M., Mahometa, M., et al. (2010). Validation of a 3-dimensional laser body scanner for assessment of waist and hip circumference. Journal of the American College of Nutrition, 29(3), 179-188.

33. Jaeschke, L., Steinbrecher, A., \& Pischon, T. (2015). Measurement of waist and hip circumference with a body surface scanner:
Feasibility, validity, reliability, and correlations with markers of the metabolic syndrome. PLOS ONE, 10(3), e0119430. https://doi. org/10.1371/journal.pone.0119430.

34. Park, B. K., \& Reed, M. P. (2015). Parametric body shape model of standing children aged 3-11 years. Ergonomics, 58(10), 1714 1725. https://doi.org/10.1080/00140139.2015.1033480.

35. Park, B. K., Lumeng, J. C., Lumeng, C. N., Ebert, S. M., \& Reed, M. P. (2015). Child body shape measurement using depth cameras and a statistical body shape model. Ergonomics, 58(2), 301-309. https://doi.org/10.1080/00140139.2014.965754.

36. Pagano, B. T., Parkinson, M. B., \& Reed, M. P. (2015). An updated estimate of the body dimensions of US children. Ergonomics, 58(6), 1045-1057. https://doi.org/10.1080/00140139.2014.10003 92.

37. Pierola, A., Epifanio, I., \& Alemany, S. (2017). Child t-shirt size data set from 3D body scanner anthropometric measurements and a questionnaire. Data Brief, 11, 311-315. https://doi. org/10.1016/j.dib.2017.02.025. 